\title{
Clinical value of surfactant protein-A in serum and sputum for pulmonary tuberculosis diagnosis
}

\author{
H. Hu, G.L. Teng, L.Z. Gai, Y. Yang and C.J. Zhu \\ Department of Respiratory Medicine, Chest Hospital, Shandong, China \\ Corresponding author: $\mathrm{H}$. $\mathrm{Hu}$ \\ E-mail: huahucn@126.com
}

Genet. Mol. Res. 12 (4): 4918-4924 (2013)

Received March 17, 2013

Accepted August 30, 2013

Published October 24, 2013

DOI http://dx.doi.org/10.4238/2013.October.24.2

\begin{abstract}
The aim of this study was to explore the diagnostic and differential diagnosis value of surfactant protein-A (SP-A) in the serum and sputum for pulmonary tuberculosis. A total of 101 patients with pulmonary tuberculosis, 85 healthy volunteers, and 30 chronic obstructive pulmonary disease (COPD) patients were divided into pulmonary tuberculosis group, healthy control group, and COPD group, respectively. SP-A was determined in the serum and sputum in the three groups by enzyme-linked immunosorbent assay. The expression of SP-A in serum was significantly higher $(\mathrm{P}<0.05)$ in the pulmonary tuberculosis group than in the healthy control and COPD groups. There were no differences in the SP-A expression in the sputum among the three groups. There was no significant effect of gender, age, tubercle bacillus antibodies, tuberculin purified protein derivative trial, leukocyte count, neutrophilic granulocyte, lymphocyte percentage, or lung cavities on SP-A levels in serum or sputum for the pulmonary tuberculosis group $(\mathrm{P}>0.05)$. The detection of SP-A in serum and sputum was shown to be of great value for the diagnosis and differential diagnosis of pulmonary tuberculosis, and therefore merits further investigation.
\end{abstract}

Key words: Tuberculosis; Pulmonary; Sputum; Surfactant protein-A; Diagnosis 


\section{INTRODUCTION}

Mycobacterium tuberculosis remains an important cause of pulmonary infectious diseases throughout the world, especially in developing countries such as India and Africa, among others (Read, 1996). The most important current concerns related to M. tuberculosis involve the increased prevalence of drug resistant strains, which are becoming more and more difficult to control, and thereby result in increased death rates due to $M$. tuberculosis infection. Indeed, approximately $1 / 3$ of global tuberculosis cases result in death each year (Bloom and Murray, 1992; Raviglione et al., 1995). The most common diagnosis criterion remains screening for the tuberculosis strain in sputum; however, in our clinic, in several positive cases, results of testing for tubercle bacillus in sputum were negative. Therefore, new and more effective diagnostic tools for pulmonary tuberculosis are urgently needed.

Surfactant protein-A (SP-A), which is the most abundant hydrophilic protein, is synthesized and secreted by type II epithelial cells in the lung (Wright, 1997), and is mainly present in the pulmonary surfactant. SP-A is a C-type lectin and contains a carbohydrate recognition domain (Hawgood, 1989; Hawgood and Shiffer, 1991), which shares several structural features with the human complement factor C1Q and the mannose-binding protein. SP-A is thought to play an important role in the modulation of the inflammatory and immunological response (Bobak et al., 1987; Wright, 1997). SP-A contributes to phospholipid homeostasis in the lung, and participates in host defense against pulmonary pathogens. In the last few decades, in vitro studies revealed that SP-A functioned as an opsonin and enhanced the ingestion of a number of widespread pathogens (Voss et al., 1988; Tenner et al., 1989; van Iwaarden, 1991; McNeely and Coonrod, 1994), including Bacillus Calmette-Guerin (BCG), M. tuberculosis, influenza A virus, Escherichia coli, Hemophilus influenzae, Staphylococcus aureus, Streptococcus pneumoniae, Mycoplasma pulmonis, and Klebsiella pneumoniae, among others (Weikert et al., 2000). Indeed, several researchers have found correlations between SP-A levels in body fluids with infectious lung diseases.

Therefore, the aim of the present study was to investigate the diagnostic value of the levels of SP-A in serum and sputum for pulmonary tuberculosis. We selected patients with definite diagnoses of pulmonary tuberculosis, and further included healthy and chronic obstructive pulmonary disease (COPD) subjects as control groups. SP-A levels in serum and sputum were determined by enzyme-linked immunosorbent assay (ELISA). Serum and sputum were used because blood samples are easily obtained in the clinic, and can be controlled under many conditions. Sputum samples are particularly easy to collect because it is a non-invasive and non-traumatic process for participants, allowing the trial to proceed smoothly.

\section{MATERIAL AND METHODS}

\section{Patient selection}

A total of 101 pulmonary tuberculosis patients who were admitted to the Chest Hospital (Shandong, China) from October 2007 to October 2010 were included in the study (pulmonary tuberculosis group); 62 patients were men and 39 were women, with a mean age of $34 \pm 18$ years. This study was conducted in accordance with the declaration of Helsinki and with approval from the Ethics Committee of the Department of Respiratory Medicine, Chest 
Hospital, Shandong, China. Written informed consent was obtained from all participants. The diagnosis standard for tuberculosis was based on the 2006 tuberculosis guide. Thirty patients (17 men, 13 women) with COPD were chosen as the control disease group (COPD group), with a mean age of $37 \pm 13$ years. The diagnosis criteria of COPD were based on the Global initiative of Obstructive Lung Disease (GOLD) classification (2006); the most serious degree was grade II, and all patients were in the non-acute stage. Additionally, 85 healthy volunteers (47 men, 38 women), who came to the clinic for physical examinations, were chosen to form the healthy control group. Their mean age was $38 \pm 16$ years. Criteria for the healthy group included normal number of leukocytes and neutrophils in peripheral blood, normal sedimentation, and chest radiographs clearly indicated no tuberculin purified protein derivatives (PPD).

\section{Methods}

Approximately $3 \mathrm{~mL}$ venous blood was drawn in the morning from fasted patients. Blood samples were centrifuged at $1000 \mathrm{rpm}$ for $10 \mathrm{~min}$, and the supernatant was collected and stored at $-20^{\circ} \mathrm{C}$. The sputum was collected in the same way. However, the standard sputum must be determined in order to ensure accuracy of the trial. Optical microscope observations in a low power field revealed that the average number of the epithelial cells was $<10$ and the average number of leukocytes was $>25$. SP-A and tubercle bacillus antibody levels were determined by ELISA. The PPD trial was executed with the Mantoux method. The erythrocyte sedimentation rate, leukocyte count, neutrophilic granulocyte percentage, and lymphocyte percentage were all calculated in the Chest Hospital. Thorax computed tomography (CT) scans were performed in the image department of the Chest Hospital.

\section{Statistical analysis}

The SPSS16.0 statistical software was used to analyze the obtained data for statistical significance. The Kruskal-Wallis test was used for the comparison of the three groups. Spearman rank correlation and chi-squared tests were used for categorization and ranked data; $\mathrm{P}<$ 0.05 was considered statistically significant.

\section{RESULTS}

\section{Serum SP-A levels}

Results of the Kruskal-Wallis test revealed that SP-A levels of serum were highest in the pulmonary tuberculosis group, followed by the healthy group, and were lowest in the COPD group (Table 1$)$. The difference among the groups was statistically significant $\left(\chi^{2}=\right.$ 77.402, $\mathrm{P}<0.05)$.

\section{Sputum SP-A levels}

The Kruskal Wallis test revealed no significant difference in sputum SP-A levels among the three groups $\left(\chi^{2}=0.228, \mathrm{P}=0.892\right)$ (Table 2 ). 
Table 1. Level of serum SP-A of the patients in pulmonary tuberculosis group, chronic obstructive pulmonary disease (COPD) group, and health group.

\begin{tabular}{lrr}
\hline Group & $\mathrm{N}$ & Mean rank \\
\hline Pulmonary tuberculosis group & 101 & 144.65 \\
COPD group & 30 & 41.18 \\
Health group & 85 & 88.65 \\
Total & 216 & 85 \\
\hline
\end{tabular}

Table 2. Level of sputum SP-A of the patients in Pulmonary tuberculosis group, chronic obstructive pulmonary disease (COPD) group, and health group.

\begin{tabular}{lrc}
\hline Group & N & Mean rank \\
\hline Pulmonary tuberculosis group & 101 & 106.36 \\
COPD group & 30 & 110.18 \\
Health group & 85 & 110.50 \\
Total & 216 & \\
\hline
\end{tabular}

\section{Correlation between serum SP-A levels and other factors in pulmonary tuberculosis patients}

We evaluated the correlation between several factors and serum SP-A levels in the pulmonary tuberculosis groups including gender, age, PPD trial, number of tubercle bacilli, tubercle bacillus antibodies, erythrocyte sedimentation rate, leukocyte count, neutrophilic granulocyte percentage, lymphocyte percentage, and thorax CT (hollow). Spearman rank correlation analysis demonstrated no correlation with any factor $(\mathrm{P}>$ 0.05) (Table 3).

Table 3. Correlation between many factors and serum SP-A in pulmonary tuberculosis.

\begin{tabular}{lcc}
\hline Factors & Correlation coefficient & P value \\
\hline Gender & 0.192 & 0.056 \\
Age & -0.063 & 0.534 \\
PPD trial & 0.170 & 0.091 \\
Number of tubercle bacillus in sputum & 0.108 & 0.283 \\
Tubercle bacillus antibodies & 0.090 & 0.374 \\
Erythrocyte sedimentation rate & -0.109 & 0.279 \\
Leucocyte count & 0.046 & 0.648 \\
Neutrophilic granulocyte percentage & 0.034 & 0.738 \\
Lymphocyte percentage & -0.033 & 0.745 \\
Thorax CT (hollow) & -0.042 & 0.682 \\
\hline
\end{tabular}

$\mathrm{PPD}=$ purified protein derivative CT $=$ computed tomography.

\section{Correlation between sputum SP-A and other factors in pulmonary tuberculosis patients}

We evaluated the correlation between the same factors mentioned above with sputum SP-A in the pulmonary tuberculosis group, and the results are presented in Table 4. Spearman rank correlation analysis revealed no significant correlations $(\mathrm{P}<0.05)$, with the exception of the number of tubercle bacillus in sputum, which was positively correlated with SP-A $(r=0.3$, and $\mathrm{P}=0.04$ ). 


\begin{tabular}{lcc}
\multicolumn{2}{c}{ Table 4. Correlation between many factors and sputum SP-A in pulmonary tuberculosis. } \\
\hline Factors & Correlation coefficient & P value \\
\hline Gender & 0.087 & 0.388 \\
Age & -0.145 & 0.150 \\
PPD trial & 0.198 & 0.048 \\
Number of tubercle bacillus in sputum & -0.023 & 0.04 \\
Tubercle bacillus antibodies & 0.017 & 0.824 \\
Erythrocyte sedimentation rate & -0.152 & 0.863 \\
Leucocyte count & -0.143 & 0.130 \\
Neutrophilic granulocyte percentage & 0.093 & 0.155 \\
Lymphocyte percentage & -0.053 & 0.358 \\
Thorax CT (hollow) & & 0.600 \\
\hline For abbreviation, see legend to table 3
\end{tabular}

For abbreviation, see legend to table 3.

\section{DISCUSSION}

Pulmonary tuberculosis is an important cause of pulmonary disease throughout the world, particularly in developing countries, and is the leading cause of death from a single infectious disease (Anonymous, 1983). Therefore, it is essential to find new and effective methods for improving the diagnosis rate of tuberculosis. The pulmonary surfactant is a lipoprotein complex lining the lung surface, which consists of phospholipids, specific proteins, and other lipid components. The surfactant is synthesized by alveolar type II epithelial cells, assembled in lamellar bodies of the intracellular surfactant storage organelle, and secreted into the alveolar space and terminal airways where it functions. The pulmonary surfactant is essential for reducing surface tension at the air-liquid interface of the lung (Wu et al., 2006). Maintenance of surface tension is essential for the diffusion of oxygen and carbon dioxide between inspired air and circulation. Surfactant proteins (SPs) make up 10\% of the pulmonary surfactant, and comprise a large protein family. Four SPs are known: SP-A, SP-B, SP-C, and SP-D, with SP-A and SP-D being the most important.

Some researchers have found that SP-A levels in bronchoalveolar lavage and serum were associated with a multitude of pulmonary inflammatory diseases (Sorensen et al., 2007). In addition, accumulating evidence in mouse models of infection and inflammation indicates that recombinant forms of SPs are biologically active in vivo, and may therefore have therapeutic potential for controlling pulmonary inflammatory diseases. Infection or sepsis may be implicated in the pathogenesis of some of the pulmonary diseases for which SP-A has been suggested as a biomarker. Several studies have demonstrated strong associations between SP-A levels and various pulmonary diseases, including respiratory-distress syndrome, acute respiratory-distress syndrome (Ikegami et al., 2006), acute lung injury (Inase et al., 2006), interstitial lung disease (Takahashi et al., 2006), pulmonary alveolar proteinosis (Nadesalingam et al., 2005), idiopathic pulmonary fibrosis (Vazquez de Lara et al., 2000, 2003), collagen vascular diseases (Kankavi, 2006), asthma, allergies, COPD, and others (Clark and Reid, 2003). Gold et al. (2004) evaluated SP-A levels from pulmonary tuberculosis patients pretherapy and post-treatment in the alveolar lavage fluid, and found much higher SP-A levels post-treatment.

In the present study, we evaluated SP-A levels in serum from pulmonary tuberculosis patients, using healthy and COPD patients as control groups. SP-A levels were highest in the pulmonary tuberculosis group, followed by the healthy group, with the lowest levels observed in the COPD group. There are several hypotheses to explain the role of SP-A in the serum. 
Alveolar II epithelial cells synthesize and secrete the SP-A, and a concentration gradient exists between the alveolar cells and blood circulation. When pulmonary injury occurs, vascular permeability increases, and the air-blood barrier is destroyed, which reduces SP-A metabolism, thus increasing the SP-A level in serum. I In addition, the leakage of pulmonary tuberculosis may also increase SP-A level (Jobe et al., 1983). In blood, the mechanism of clearance also results in increasing the SP-A content in pulmonary tuberculosis. Therefore, the specific mechanism is currently unclear, and is worth further study.

In contrast, results of the present study clearly demonstrated no obvious differences in SP-A levels in sputum among the three groups. A previous study demonstrated that the SP-A level of bronchoalveolar lavage fluid was much lower in pulmonary tuberculosis than in other pulmonary diseases (Jobe et al., 1983). In the present study, SP-A levels of sputum varied substantially among patients and the data were not normally distributed. One possibility for this variation could be that some of the patients were treated with anti-tuberculosis medication. Additionally, SP-A levels were similar between injured and healthy pulmonary segments, suggesting that the sputum maybe not be an ideal diagnostic tool, despite its convenience with respect to sample collection. This result should be further clarified using a larger sample size.

In general, pulmonary tuberculosis is closely related with many factors, such as age, gender, tubercle bacillus antibodies, PPD trial, leukocyte count, neutrophilic granulocytes, lymphocyte percentage, and lung cavities, which are all usually used for diagnosis. In the present study, we found that SP-A was not closely related with any of these factors; however, in combination with some of these factors, the rate of diagnosis of pulmonary tuberculosis could be improved (data not shown).

SP-A levels in serum and sputum were shown to be suitable makers for pulmonary tuberculosis. SP-A therefore shows great potential as a maker for improving the sensitivity, accuracy, and specificity of the diagnosis of pulmonary tuberculosis, which should be explored further.

\section{ACKNOWLEDGEMENTS}

We thank the Department of Science and Technology of Shandong province for funding and the International Hanguang Infection Disease Research Center for support in trial processing.

\section{REFERENCES}

Anonymous (1983). Plan of action for research in the immunology of tuberculosis: memorandum from a WHO meeting. Bull. World Health Organ 61: 779-785.

Bloom BR and Murray CJ (1992). Tuberculosis: commentary on a reemergent killer. Science 257: 1055-1064.

Bobak DA, Gaither TA, Frank MM and Tenner AJ (1987). Modulation of FcR function by complement: subcomponent C1q enhances the phagocytosis of IgG-opsonized targets by human monocytes and culture-derived macrophages. $J$. Immunol. 138: 1150-1156.

Clark H and Reid K (2003). The potential of recombinant surfactant protein D therapy to reduce inflammation in neonatal chronic lung disease, cystic fibrosis, and emphysema. Arch. Dis. Child. 88: 981-984.

Gold JA, Hoshino Y, Tanaka N, Rom WN, et al. (2004). Surfactant protein A modulates the inflammatory response in macrophages during tuberculosis. Infect. Immun. 72: 645-650.

Hawgood S (1989). Pulmonary surfactant apoproteins: a review of protein and genomic structure. Am. J. Physiol. 257: L13-L22.

Hawgood S and Shiffer K (1991). Structures and properties of the surfactant-associated proteins. Annu. Rev. Physiol. 53: 375-394.

Ikegami M, Carter K, Bishop K, Yadav A, et al. (2006). Intratracheal recombinant surfactant protein d prevents endotoxin 
shock in the newborn preterm lamb. Am. J. Respir. Crit. Care Med. 173: 1342-1347.

Inase N, Ohtani Y, Sumi Y, Umino T, et al. (2006). A clinical study of hypersensitivity pneumonitis presumably caused by feather duvets. Ann. Allergy Asthma Immunol. 96: 98-104.

Jobe A, Ikegami M, Jacobs H, Jones S, et al. (1983). Permeability of premature lamb lungs to protein and the effect of surfactant on that permeability. J. Appl. Physiol. 55: 169-176.

Kankavi O (2006). Increased expression of surfactant protein A and D in rheumatoid arthritic synovial fluid (RASF). Croat. Med. J. 47: 155-161.

McNeely TB and Coonrod JD (1994). Aggregation and opsonization of type A but not type B Hemophilus influenzae by surfactant protein A. Am. J. Respir. Cell Mol. Biol. 11: 114-122.

Nadesalingam J, Reid KB and Palaniyar N (2005). Collectin surfactant protein D binds antibodies and interlinks innate and adaptive immune systems. FEBS Lett. 579: 4449-4453.

Raviglione MC, Snider DE, Jr. and Kochi A (1995). Global epidemiology of tuberculosis. Morbidity and mortality of a worldwide epidemic. JAMA 273: 220-226.

Read C (1996). Mycobacterium tuberculosis: a stowaway in the cell. Lancet 348: 50.

Sorensen GL, Husby S and Holmskov U (2007). Surfactant protein A and surfactant protein D variation in pulmonary disease. Immunobiology 212: 381-416.

Takahashi H, Shiratori M, Kanai A, Chiba H, et al. (2006). Monitoring markers of disease activity for interstitial lung diseases with serum surfactant proteins A and D. Respirology 11 Suppl: S51-S54.

Tenner AJ, Robinson SL, Borchelt J and Wright JR (1989). Human pulmonary surfactant protein (SP-A), a protein structurally homologous to C1q, can enhance FcR- and CR1-mediated phagocytosis. J. Biol. Chem. 264: 1392313928.

van Iwaarden JF, van Strijp JA, Ebskamp MJ, Welmers AC, et al. (1991). Surfactant protein A is opsonin in phagocytosis of herpes simplex virus type 1 by rat alveolar macrophages. Am. J. Physiol. 261: L204-L209.

Vazquez de Lara L, Becerril C, Montano M, Ramos C, et al. (2000). Surfactant components modulate fibroblast apoptosis and type I collagen and collagenase-1 expression. Am. J. Physiol. Lung Cell Mol. Physiol. 279: L950-L957.

Vazquez de Lara LG, Umstead TM, Davis SE and Phelps DS (2003). Surfactant protein A increases matrix metalloproteinase-9 production by THP-1 cells. Am. J. Physiol. Lung Cell Mol. Physiol. 285: L899-L906.

Voss T, Eistetter H, Schafer KP and Engel J (1988). Macromolecular organization of natural and recombinant lung surfactant protein SP 28-36. Structural homology with the complement factor C1q. J. Mol. Biol. 201: 219-227.

Weikert LF, Lopez JP, Abdolrasulnia R, Chroneos ZC, et al. (2000). Surfactant protein A enhances mycobacterial killing by rat macrophages through a nitric oxide-dependent pathway. Am. J. Physiol. Lung Cell Mol. Physiol. 279: L216-L223.

Wright JR (1997). Immunomodulatory functions of surfactant. Physiol. Rev. 77: 931-962.

Wu YZ, Manevich Y, Baldwin JL, Dodia C, et al. (2006). Interaction of surfactant protein A with peroxiredoxin 6 regulates phospholipase A2 activity. J. Biol. Chem. 281: 7515-7525. 